\title{
ТЕОРЕТИЧЕСКИЕ ВОПРОСЫ И ПРАКТИЧЕСКИЕ АСПЕКТЫ ОРГАНИЗАЦИИ СОВРЕМЕННОЙ СИСТЕМЫ КОРПОРАТИВНОГО ОБУЧЕНИЯ РАБОТНИКОВ
}

\author{
(c) 2021 Твердохлебова Татьяна Валерьевна \\ кандидат экономических наук, доцент \\ Институт управления бизнес-процессами \\ Сибирский федеральный университет, Россия, Красноярск \\ () 2021 Левченко Лариса Владимировна \\ кандидат экономических наук, доцент, ст. научный сотрудник \\ ГБНОУ СО «Академия для одаренных детей (Наяновой)», Россия, Самара \\ E-mail: lvls@mail.ru
}

В статье исследуются теоретические вопросы корпоративного образования и обучения работников современных организаций. Выделяются цели проведения обучения, даются различные трактовки понятия обучения и корпоративного образования, характеризуются его организационные формы и виды. Рассматривается понятие андрагогики и выявляются условия успешного обучения взрослых людей. Также характеризуются практические аспекты организации современной системы корпоративного обучения работников на примере золотодобывающей компании.

Ключевые слова: корпоративное обучение, интеллектуальный капитал, человеческий капитал, андрагогика, система корпоративной подготовки кадров, коучинг, мобильное обучение, дистанционное обучение.

В современных условиях общественноэкономического развития происходят кардинальные изменения в функционировании организаций и производственных компаний, что находит свое отражение в обновлении трудовых, организационных, технологических и бизнес-процессов: внедряются инновационные технологии, активно осуществляется цифровая трансформация производства и управления, используются новейшие информационные системы и др. При этом одним из важнейших факторов для реализации этих изменений и осуществления процессов модернизации производства является наличие квалифицированных работников, обладающих современными профессиональными знаниями, техническими и функциональными компетенциями, совокупность которых формирует интеллектуальный капитал компании. В этой связи здесь уместным будет отметить, что согласно традиционному определению человеческого капитала*, представляющего собой накопленный запас здоровья, знаний, умений, навыков, способностей, мотиваций, жизненной энергии и т.п., его важ- нейшей частью является интеллектуальный капитал. Как известно, интеллектуальный капитал представляет собой комплекс интеллектуальных знаний, навыков и умений человека, который должен постоянно развиваться и пополняться**, а этому может эффективно содействовать корпоративное профессиональное обучение на непрерывной основе.

Научные исследования отечественных и зарубежных специалистов, а также практическая деятельность наиболее успешных организаций и предприятий подтверждают, что инвестиции в человеческий и интеллектуальный капитал, в том числе формирование мотивации и создание условий для профессионального развития работников, повышения их квалификации, обеспечивают большую эффективность, чем средства, направленные, например, только на техническое или технологическое обновление производства. Поэтому сегодня многие как зарубежные, так и отечественные компании, все чаще начинают рассматривать затраты, связанные с обучением и переобучением персонала, повышением его квалификации, как приоритетные, а финанси-

* Левченко Л. В., Карпенко О.А. Человеческий капитал и современные тенденции его развития // Вопросы экономики и права. 2019. № 137. С. 36-41.

** ЛевченкоЛ.В. Интеллектуальный капитал: методологические принципы и методы научного познания // Вестник Омского университета. Серия: Экономика. 2013. № 3. С. 143-147. 
рование корпоративной системы обучения как наиболее выгодные инвестиции*.

Характеризуя профессиональное обучение следует прежде отметить, что в научной и учебной литературе понятия «обучение» и «развитие персонала» являются часто используемыми терминами. При этом понятие «развитие» - более широкое и общее, а «обучение» рассматривается как одна из функций профессионального развития.

Когда речь идет о «развитии персонала», то рассматривают его как процесс, включающий в себя подготовку работников к выполнению новых производственных задач, переподготовку кадров для замещения новых рабочих мест, карьерную и профессиональную ротацию, формирование стратегического и оперативного кадрового резерва. Основными элементами системы развития персонала являются профессиональное обучение сотрудников, управление карьерой, формирование и развитие кадрового резерва ${ }^{* *}$.

Согласно общепринятой трактовке, «обучение» представляет собой процесс формирования у обучающегося новых знаний и/или новых навыков и компетенций. Профессиональное обучение предполагает как теоретическую, так и практическую подготовку. Корпоративное профессиональное обучение рассматривается как систематический процесс обучения сотрудников, который инициируется, управляется и организуется компанией для получения работниками новых профессиональных знаний, более высокой квалификации, формирования и развития новых практических навыков и компетенций, с тем чтобы в конечном итоге способствовать повышению экономической эффективности деятельности предприятия.

Обучение принято рассматривать как непрерывный процесс (поток) обучения, или как отдельное обучающее мероприятие.

В первом случае, обучение представляет собой непрерывный процесс формирования и развития различных профессиональное знаний и навыков работников с учетом соответствия обучения конкретным принципам, целям и стратегии развития предприятия, например, повыше- ние эффективности работы компании, переход на экологические технологии производства, расширение ассортимента и повышение качества выпускаемой продукции (работ, услуг); рост конкурентоспособности организации и др.

Во втором случае, когда речь идет об обучении как отдельном мероприятии, оно представляет собой разовый процесс получения новых знаний и навыков и, как правило, нацелено на решение строго определенной задачи.

При организации обучения необходимо четко и однозначно формулировать цель процесса обучения или конкретного обучающего мероприятия, а также ее рекомендуется фиксировать в соответствующих документах (например, техническое задание при формировании учебной программы). Следует учитывать, что от цели обучения во многом зависит выбор тех или иных педагогических технологий, методик обучения, методов и приемов обучения, форм занятий, набора средств обучения и т.д. К тому же четко обозначенная цель помогает подвести итоги, определить эффективность и необходимость продолжения обучения.

Характеризуя цели обучения, можно отметить, что при существующем в научных источниках множестве их классификаций и перечней, наиболее распространенными являются следующие две $\mathrm{e}^{\text {**** }}$ :

Первая цель - обучение жестким знаниям и навыкам (hard skills), которые можно легко проверить на экзамене или посредством тестирования, и которые больше требуются на низких или начальных ступенях профессионального развития, например, знание техники безопасности, навыки вождения автомобиля, умение обслуживать и осуществлять ремонт оборудования, владение компьютерными программами на уровне пользователя, умение набирать текст на компьютере, и др.;

Вторая цель - обучение мягким качественным коммуникативным и управленческим навыкам (soft skills), которые сложно измерить количественно, и которые в основном требуются на управленческих и вышестоящих должностях, например, интеллектуальное развитие, креативность мышления, умение работать в команде,

\footnotetext{
* ЛевченкоЛ.В., Карпенко О.А. Человеческий капитал и современные тенденции его развития // Вопросы экономики и права. 2019. № 137. С. 42-43.

** Соловьёв Д.П. Обучение и развитие персонала: учеб.пособие / Д. П. Соловьёв, Л.А. Илюхина.-Самара: Издво Самар. гос. экон. ун-та, 2019. С. 6.

*** Там же, с.9.
} 
умение делегировать полномочия и др.

Современная жизнь и глобальные изменения в научно-технологическом развитии производства диктуют, что обучение должно продолжаться на протяжении всей жизни и профессиональной деятельности человека, и здесь доминирующее место все больше занимает корпоративное обучение, которое становится наиболее удобным и результативным для работника, т.к. в большей степени приспособлено к реальному производственному процессу, отражает его специфику, учитывает направления его инновационного развития и напрямую подчинено конкретным целям и задачам развития компании.

В настоящее время корпоративное образование рассматривается как одна из важнейших подсистем непрерывного образования. Здесь важно обратить внимание, что, несмотря на близость понятий «корпоративное обучение» и «корпоративное образование», все же их необходимо уточнить. Так, «корпоративное обучение»это процесс, как это выше уже нами отмечалось, а «корпоративное образование - это система знаний, которая предполагает накопление и трансляцию (передачу) различного рода знаний: экономических, технологических, производственных, организационных, знаний в области корпоративной культуры, профессиональноэтических, управленческих и других для эффективного достижения поставленных перед корпорацией целей»*.

Корпоративное обучение - динамичный процесс, в ходе которого происходит передача, распространение, обновление профессиональных знаний, повышение квалификации, формирование новых компетенций и навыков, нацеленных на решение конкретных производственных задач, на эффективное достижение обозначенных компанией целей. При этом сами работники организации, пройдя обучение или в процессе его прохождения, могут изменять сложившуюся производственную среду, выработать новые модели производственной деятельности, усовершенствовать технологические и бизнеспроцессы компании, что, безусловно, повышает эффективность основной задачи обучения.

Сущность корпоративного обучения заклю- чается не только в повышении уровня квалификации персонала компании, в обновлении профессиональных знаний и опыта, навыков и компетенций, но и в увеличении у работников их потенциала активности, адаптивности, устойчивости, изменчивости, способности к гибкому мышлению.

Корпоративное обучение в настоящее время развивается стремительно и набирает обороты, при этом в российских компаниях становится все более востребованным обучение и переобучение не только управленческих кадров, инженерно-технических работников, но и специалистов рабочих профессий. Ввиду массового развития новых интеллектуальных технологий и необходимости осваивать новейшее оборудование, производственные системы и циклы объективно возникает потребность проводить корпоративное обучение сотрудников на новой основе. И здесь работодатель вынужден обновлять подходы к обучению и повышению квалификации, разрабатывать систему переквалификации, дополнительного обучения, сертификации работников и др. Приобретенные в процессе обновленного модернизированного с учетом современных требований корпоративного обучения новые профессиональные знания и компетенции позволяют повысить эффективность деятельности компании, а также способствуют повышению конкурентоспособности предприятия как на внутреннем рынке, так и на международном уровне.

О финансировании корпоративного обучения и образования в мировой и отечественной практике свидетельствуют следующие данные. Так, например, расходы на корпоративное образование в США в 2015 году составили в среднем 1252 доллара на сотрудника. Аналогичным образом во Франции на корпоративное обучение персонала тратится около 30 млрд. долларов в год, в Великобритании - почти 40 млрд. долларов. Российский рынок корпоративного и дополнительного образования в 2016 году по данным университета «Нетология» был оценен всего в 105,1 млрд. рублей (это 1,5 млрд. долл. по курсу 70 руб. за 1 долл. на 22.10.2021), что в десятки раз меньше, чем в Западной Европе ${ }^{* *}$.

Рассматривая корпоративное обучение,

\footnotetext{
* Родин А.И. Система корпоративного обучения как серьезный фактор профессионального развития кадров образовательной организации URL: https://prodod.moscow/archives/1413

** Левченко Л. В., Карпенко О.А. Человеческий капитал и современные тенденции его развития // Вопросы экономики и права. 2019. № 137. С. 36-43
} 
остановимся на основных его формах - это индивидуальные и групповые. Наиболее эффективными обучающими и развивающими формами корпоративного обучения считаются групповые (коллективные, командные), так как помимо самого обучения они параллельно еще и развивают навыки коммуникации и эффективного взаимодействия в группе, развивают индивидуальность и ролевые компетенции, межличностное взаимодействие и др.

Групповое обучение предпочтительно еще и тем, что дает синергетический эффект, при котором эффект от обучения группы значительно превосходит суммарный эффект от индивидуального обучения. Это происходит в связи с тем, что в групповом обучении изменяется мышление, сознание и мотивация обучаемых. Такое обучение нацелено на достижение слаженного взаимодействия друг с другом всех членов группы, позволяет выработать навыки совместного решения поставленной задачи с наибольшим эффектом в оптимальные сроки.

Индивидуальное же обучение, как правило, проходит по более индивидуальной программе, когда обучаемый может изменять учебный процесс, участвовать в выборе методов обучения, а также может получать более полно различные знания, больше задавать вопросов, осваивать производственные компетенции под руководством индивидуального наставника и т.д.

Наряду с этим корпоративное обучение бывает внутренним и внешним.

Внутреннее обучение персонала представляет собой обучение работников самой организацией и в основном ориентировано на обучение персонала низшего или среднего звена. Его основными формами служат и теоретические и практические занятия, в том числе лекции, практические семинары, круглые столы и конференции, тренинги, коучинг, наставничество, методические занятия и т.д. Положительные стороны такого обучения - это прежде всего, его практическая направленность, меньшие издержки на обучение при большей эффективности, учет специфики организации, учет актуальности вопросов/проблем для данного предприятия, контроль за всем процессом обучения и промежуточными/итоговыми результатами обучения, более быстрая адаптация работников к процессу обучения и др. Среди отрицательных моментов внутрифирменного обучения можно выделить, например, отвлечение сотрудника от занятий для выполнения им каких-либо срочных производственных заданий, отсутствие возможности обмениваться опытом, информацией с работниками других организаций.

Внешнее корпоративное обучение проводится фирмами/организациями, предоставляющими специализированные услуги по обучению персонала. Среди его распространенных форм - получение второго и последующего высших образований, повышение квалификации, получение дополнительного образования, конференции, стажировки, практики и т.д.

При этом замечено, что крупные компании в первую очередь и в большем объеме тратят средства на обучение руководящего состава. В период 2015-2017 годов, согласно обзору рынка корпоративного образования, в рамках внешнего обучения превалировали образовательные программы для руководителей. По данным исследования «Аналитики РШУ» в 2018 году 45,7\% организаций планировали предоставить обучение своего персонала топ-менеджменту, для сравнения - в 2017 году таких организаций было $35,6 \%$.

Внешнее обучение имеет несомненные достоинства, поскольку сотрудники получают возможность: отключиться от текущих дел и погрузиться в процесс обучения, получить новую информацию и идеи, сделать сравнительный анализ производственных процессов на основе обмена опытом и информацией с обучающимися-представителями других компаний, получить возможность пройти обучения, как правило, у высококвалифицированных педагогов или специалистов в свое направлении по уникальным образовательным программам, владеющими современными образовательными технологиями и интерактивными методами обучения и др. Вместе с тем, у внешнего обучения есть свои отрицательные стороны: отмечается преобладание теоретического обучения и слабая практическая направленность; в меньшей степени или вообще не учитывается специфика организации, где работает сотрудник; относительно большие затраты на обучение по сравнению с внутренним обучением; меньшая эффективность обучения из-за того, что нередко отсутствуют самоконтроль и мотивация

\footnotetext{
* Корпоративное обучение персонала: что это и какие виды бывают. URL: https://planfact.io/blog/posts/ korporativnoe-obuchenie-personala
} 
у обучающихся сотрудников, которые зачастую воспринимают обучение как дополнительный отпуск; со стороны компании часто не отлажена действенная система оперативного и итогового контроля, а также оценки результативности внешнего обучения и др.

В российских организациях преобладает внутреннее обучение, что показало совместное исследование компаний КPMG и АМТ-ГРУПП, проведенное в 2016 г. В больших организациях, как правило, свыше 80\% обучающихся по внутренним программам представлено рабочим персоналом с большой текучестью. И вновь прибывшие работники проходят только внутреннее обучение. На обучение сотрудников низового звена приходится значительно больше трудозатрат, чем на обучение специалистов и руководителей. Например, если в отделе обучения промышленного предприятия работают три специалиста, то два заняты организацией обучения рабочих и один - организацией обучения специалистов и руководителей. Последний еще несет ответственность за учебную, производственную и преддипломную практики студентов университетов.

В последние годы в сфере профессионального образования широкое распространение получило мобильное обучение, которое базируется на информационных и цифровых технологиях, предполагает использование мобильных и портативных ИТ-устройств, Интернета и специальных обучающих программ. Такое профессиональное обучение обладает многими достоинствами, и прежде всего - это возможность обучаться в любом месте, в любое время, без отрыва от профессиональной деятельности, сочетая работу и обучение, то есть реализуется формат дистанционного обучения. Кроме того, эта форма обучения, в отличие от традиционной, стимулирует большую активность у обучающегося в поиске и освоении новых знаний, развивает навыки самообразования, предоставляет быстрый доступ к различным информационным источникам.

Вместе с рассмотренными классификациями видов обучения существует еще одна: формальное обучение и неформальное обучение.

Формальное обучение - это обучение, которое организуется в учебных заведениях, например, в колледже или вузе, а также на площадках учебных центров и других образовательных учреждений, где проводятся различные курсы профессиональной подготовки, переподготовки, повышения квалификации и т.д. В этом случае обучающийся сотрудник непосредственно общается со своим преподавателем (наставником, тренером).

Неформальное обучение предполагает получение информации, профессиональных знаний и формирование навыков/компетенций при помощи коллег, руководителя в организации, а также самостоятельное обучение посредством специальной литературы, а также из Интернетисточников по собственной инициативе работника. В научных источниках имеются настоящее время результаты исследований, в соответствии с которыми развитие, например, управленческих компетенций и гибких навыков вызвано на 70\% использованием неформального обучения и только на 30\% - формального. В настоящее время стала наблюдаться устойчивая тенденция: многие организации и даже крупные компании все чаще поощряют самостоятельное обучение и развитие своего персонала, что позволяет им существенно экономить затраты на обучение.

Как отмечалось выше, корпоративное профессиональное обучение проводится непосредственно в компании для ее сотрудников. Посредством организации корпоративного обучения осуществляются обучение, переобучение сотрудников и повышение их профессионализма и квалификации. Корпоративным обучением персонала должны заниматься специально обученные люди с педагогическим образованием. Педагогика как наука создавалась на базе особенностей развития детей, закономерностей их развития, сенситивных периодов становления и взросления. Взрослый в педагогике - это учитель (педагог), тренер, который все знает: чему учить, кого учить, когда учить и т.д. В старых постсоветских компаниях традиционное корпоративное обучение построено именно на базе этих правил. Однако наука андрагогика утверждает, что правила педагогики нельзя применять при обучении взрослых, нужны иные формы и приемы обучения.

В настоящее время в научной литературе наиболее распространенными являются следующие три определения термина «андрагогика»:

1) наука или теория понимания, поддержки и практики образования взрослых на протяжении всей жизни;

2) своеобразный специфический теоретический и практический подход, основанный на 
автономности обучающихся и преподавателей;

3) среднее между дополнительным образованием взрослых людей и преподаванием академических дисциплин.

На наш взгляд, наиболее логичным является первое определение, однако при любой трактовке андрагогики важны отношение к сотруднику как ко взрослому человеку и, соответственно, построение системы обучения внутри компании, исходя из этого отношения.

Практика показывает, что потребность в обучении у работника возникает при вполне определенных обстоятельствах. Можно выделить ряд причин или обстоятельств, которые достаточно часто способствуют новому обучению и/или стимулируют работника к переобучению, повышению его профессиональной квалификации:

- желание и возможность сделать карьеру или выйти на ее новое направление или новый уровень;

- стремление и возможность больше зарабатывать;

- принципиально новые или усложнившиеся производственные задачи и функции;

- возросшие требования со стороны руководителя и организации;

- негативная обратная связь (жалобы, претензии, брак, рекламации и др.);

- изменение технологий или внедрение новых технологических процессов;

- замена устаревших морально техники и оборудования, на аналоги нового поколения и др.

Многие из выше названных причин или обстоятельств, стимулирующих работника к обучению/переобучению/повышению квалификации, часто существуют одновременно и дополняют мотивацию к профессиональному развитию.

Как показывает практика, потребность в обучении нужно не только диагностировать, но и целенаправленно формировать. Однако делать это нужно не через использование отчетов или показателей премирования. В этом случае непосредственный руководитель на предприятии должен объяснять своим подчиненным необходимость и целесообразность профессионального обучения, наличие конкретных дополнительных бонусов, которые сможет получить работник по итогам обучения. А организаторы обучения должны предлагать только те профессиональные обучающие программы, которые по своему содержанию и практической направленности в полной мере отвечают экономическим и техническим интересам компании и ее сотрудников. Твердое понимание необходимости обучения у работников возникает, если:

- обучающая программа важна и необходима для исполнения производственных задач и профессиональных функций;

- непосредственный руководитель своим авторитетом убедил сотрудника в необходимости освоения новых навыков или в повышении квалификации;

- сотрудник самостоятельно стремится к новым знаниям;

- полученные новые знания, профессиональные компетенции позволят работнику повысить свою квалификацию, или освоить смежные профессии, что отразится на уровне его заработка и дополнительных доходах;

- для удержания клиентов требуются новые навыки и приемы;

- обучающий материал не предполагает большого объема традиционной «теории», а преобладают тренинг, работа с кейсами, деловые игры и т.п.;

- разбираемые на практических занятиях производственные ситуации или задания в деловых играх реальны, а не заимствованы из практики Google, Facebook и т.п.

Поэтому, если отсутствуют объективные причины, условия или обстоятельства, как внутренние, так и внешние, для применения новых профессиональных знаний и новых практических навыков, то обучение сотрудников будет нерезультативным. Отсюда следует вывод, что организаторы обучения должны тщательно отбирать и программы обучения. и преподавателей/тренеров с учетом их квалификационного уровня; критически оценивать предлагаемые программы и их содержание с точки зрения инновационности, практической значимости для компании, полного соответствия задачам и целям обучения*.

Еще одно важное требование к программам обучения работников - новые знания и навыки

\footnotetext{
* Карпенко О.А., ЛевченкоЛ.В. Изменения в преподавательской деятельности на современном этапе общественно-экономического развития // Современная наука: перспективы, достижения и инновации. Материалы III Международной научно-практической конференции. Составители: Б. М. Насибулина, Т. Ф. Курочкина, Р. С. Мунер. 2020. С. 102-105.
} 
должны быть актуальны в ближайшей перспективе и для самого работника, и для его компании. Как показывают исследования специалистов, уже через год забывается примерно 50\% того, что изучалось пассивно, а через два года $80 \%$. Это значит, что «опережающее обучение» работников - не всегда рационально для компании. Если новшества в организации наступят не скоро, то не следует торопиться с таким обучением. Отсутствие возможностей применить полученные знания и профессиональные навыки с одной стороны могут понизить мотивацию к обучению, а с другой - спровоцировать сотрудника на поиск новой работы, где его повышенный уровень квалификации будет востребован и более высоко оплачен.

Из сказанного выше напрашивается вывод: компания должна прагматично подходить к вопросу организации профессионального обучения, критически анализировать планируемые цели обучения, тщательно подбирать программы и обучающих специалистов, владеющих современными методиками, инновационными технологиями обучения взрослых. Если полученные знания и навыки не используются, то есть риск, что обученный сотрудник «продаст» их другой организации.

В ходе организации обучения работников компании следует учитывать жизненный и профессиональный опыт обучающегося, который часто влияет на его поведение. Это выражается в следующем: взрослые не склонны меняться; взрослые не одобряют перемен, пока не осознают их неизбежность и/или необходимость; на отношение к обучению и на его результаты влияет и предшествующий опыт обучения; все новое взрослые осваивают медленнее, чем в юности.

Следует обратить внимание еще на один аспект - амбициозные специалисты не только в большей степени мотивированы к профессиональному обучению, повышению своей квалификации, освоению новых компетенций, но и предпочитают обучаться, главным образом, неформально. Это может выразиться в том, что в каких-то вопросах их знания и навыки будут выше, чем у преподавателя. Опытный педагог должен суметь использовать этот факт, например, предлагая таким обучающимся активно участвовать в процессе обучения, привносить в обучающие ситуации собственный профессио- нальный опыт, моделировать и выполнять конкретные проекты, решать кейсы, участвовать в дискуссионных группах и т.п. В данной ситуации преподаватель выступает не столько в качестве носителя знаний, а его основная задача - стать помощником, организатором учебного процесса, чтобы обучающийся стал «со-автором» процесса собственного обучения.

В этой связи при подборе педагогических кадров для работы со взрослой аудиторией нужно ориентироваться на тех специалистов, которые готовы использовать, например, подход «задача - решение», гибкое предоставление теоретического и практического материала, актуальные производственные ситуации, педагогические приемы для стимулирования обмена опытом, групповое обсуждение профессиональных вопросов и т.д.

Совершенно очевидно, что современное профессиональное обучение работников предполагает использование разнообразных методов и приемов обучения, но приоритет остается за активными методами при широком применении современных информационных технологий и формата дистанционного обучения, которое позволяет гармонично сочетать обучение и профессиональную деятельность. Здесь будет уместным в качестве примера рассмотреть опыт организации профессионального обучения в одной из ведущих золотодобывающих компаний в современной России. В настоящее время на предприятиях Компании представители рабочих профессий составляют более $65 \%$ от общего числа сотрудников.

Динамичное развитие этой производственной Компании в условиях жесткой конкуренции в золотодобывающей сфере на мировом рынке потребовало внедрение новейших технологий, стремительной модернизации и обновления оборудования, но при этом выявило ряд существенных проблем. Наиболее остро обозначилась проблема дефицита в квалифицированном персонале рабочих профессий, способном освоить новые технологические процессы и обеспечить эффективную работу современного оборудования. Кроме того, в нашей стране государственная система подготовки рабочих кадров, сформировавшаяся еще в советское время, перестала соответствовать новым требованиям инновационного развития производства. В этих условиях, начиная с 2017 года, Компания при- 
ступила к модернизации собственной корпоративной системы обучения кадров*. Основная цель модернизации - обеспечить эффективность функционирования системы подготовки и переобучения работников Компании. К этому моменту здесь уже была создана и работала система учебно-курсовых комбинатов (УКК), сосредоточенная прежде всего на рабочих и содержащая программы их обучения и повышения квалификации.

По результатам проведения аудита действующей системы профессионального обучения рабочих были выделены 5 ключевых направлений ее развития и трансформации:

1. Установление для должностей (профессий) актуальных квалификационных требований.

2. Актуализация программ профессиональной подготовки и учебно-методических материалов.

3. Внедрение системы наставничества.

4. Повышение квалификации преподавателей учебно-курсовых комбинатов.

5. Стандартизация и автоматизация процессов обучения рабочего персонала.

Важной стартовой задачей в процессе модернизации системы профессионального обучения рабочих Компании явилась разработка матриц профессиональных компетенций. Это позволило формализовать квалификационные требования к профессиям и определить ключевые трудовые действия, выполняемые представителями основных рабочих специальностей ${ }^{* *}$. На основании этих матриц были разработаны учебно-методические комплексы (УМК), каждый из которых включает программу профессиональной подготовки рабочих, презентацию для проведения очного обучения, теоретические материалы для самостоятельного обучения, тесты для проверки теоретических знаний, порядок проведения практического обучения на рабочем месте, материалы для преподавателя.

Одновременно с этой работой Компания обеспечила повышение квалификации преподавателей учебно-курсовых комбинатов, готовых применять новые методы и современные технологии обучения. Кроме того, каждый препода- ватель, работающий в корпоративной системе обучения рабочих кадров, овладел основами андрагогики, умеет структурированно описать деятельность должности и сформировать модель компетенций, готов разрабатывать УМК, знает и применяет интерактивные методы в обучении.

В ходе модернизации системы обучения рабочих кадров в Компании была проведена стандартизация и осуществлена автоматизация процессов обучения рабочего персонала. Этот проект по стандартизации и автоматизации процессов обучения предусматривает разработку и внедрение единых стандартов обучения на всех предприятиях Компании, прозрачность бизнес-процессов для всех участников, дистанционное обучение работников, возможность работы с личных и мобильных устройств, контроль исполнения стандартов по процессам, а также защиту персональных данных обучающихся.

Для реализации данного образовательного проекта Компания осуществила комплекс важных мероприятий, провела необходимые подготовительные работы. Так, например, были разработаны регламенты по обучению рабочего персонала, оборудованы компьютерные классы, подготовлена структура каталога обучающих курсов, разработаны дистанционные курсы. Основу дистанционных курсов образуют УМК, сценарии и непосредственно сам электронный курс. Каждый дистанционный курс включает в себя как учебно-теоретические материалы, так и тесты/задания для самопроверки усвоения полученных знаний. При этом оперативно с помощью современных информационных технологий осуществляется автоматическая фиксация и передача результатов обучения преподавателю.

В рамках корпоративного образовательного проекта разработаны и применяются различные форматы дистанционного обучения: видео, тексты, слайды и другой интерактивный контент. Внедрение системы дистанционного обучения позволяет Компании оптимизировать численность преподавателей, и при этом привлекать к работе только высококвалифицированных подготовленных специалистов, что позволяет обеспечивать высокое качество подготовки рабочих кадров. Изучение теоретической части програм-

\footnotetext{
* Золотые кадры: как «Полюс» трансформировал систему подготовки рабочего персонала. Режим доступа: https://hbr-russia.ru/partner_cases/polyus/zolotie-kadri-kak-polyus-transformiroval-sistemupodgotovki-rabochegopersonala.

** ПАО «Полюс» - лидер золотодобывающей отрасли. Режим доступа: https://sdo-regional.ru/prof-post/paopolyus-lider-zolotodobyvayushchej-otrasli
} 
мы в онлайн-формате предоставляет возможность работникам проходить обучение в свое свободное время и в удобном (территориально) месте, что особенно актуально для большинства сотрудников Компании, работающих вахтовым методом в удаленных районах Сибири и Дальнего Востока.

Поддерживая и модернизируя корпоративную систему профессионального обучения ра- ботников, в основе которой заложен единый стандарт качества подготовки рабочих кадров, дистанционный формат и интерактивные методы обучения с использованием современных информационных технологий, Компания эффективно инвестирует в развитие своих сотрудников, именно этим во многом обеспечивая свое устойчивое развитие и лидирующие позиции в золотодобывающей отрасли. 